\title{
Effects of climate variability on the distribution and fishing conditions of yellowfin tuna (Thunnus albacares) in the western Indian Ocean
}

\author{
Kuo-Wei Lan • Karen Evans • Ming-An Lee
}

Received: 6 December 2011 / Accepted: 11 November 2012 / Published online: 1 December 2012

(C) The Author(s) 2012. This article is published with open access at Springerlink.com

\begin{abstract}
Variations in the abundance and distribution of pelagic tuna populations have been associated with large-scale climate indices such as the Southern Oscillation Index in the Pacific Ocean and the North Atlantic Oscillation in the Atlantic Ocean. Similarly to the Pacific and Atlantic, variability in the distribution and catch rates of tuna species have also been observed in association with the Indian Ocean Dipole (IOD), a basin-scale pattern of sea surface and subsurface temperatures that affect climate in the Indian Ocean. The environmental processes associated with the IOD that drive variability in tuna populations, however, are largely unexplored. To better understand these processes, we investigated longline catch rates of yellowfin tuna and their distributions in the western Indian Ocean in relation to IOD events, sea surface water temperatures (SST) and estimates of net primary productivity (NPP). Catch per unit effort (CPUE) was observed to be negatively correlated to the IOD with a periodicity centred around 4 years. During positive IOD events, SSTs were relatively higher, NPP was lower, CPUE decreased and catch distributions were restricted to the northern and western margins of the western Indian Ocean. During negative IOD events, lower SSTs and higher NPP were associated with increasing CPUE, particularly in the Arabian Sea and seas surrounding Madagascar, and catches expanded into central regions of the western Indian Ocean. These findings provide preliminary insights into some of the key environmental features driving the distribution of yellowfin tuna in the western Indian Ocean and associated variability in fisheries catches.
\end{abstract}

This article is part of the Special Issue on "Climate and Oceanic Fisheries" with Guest Editor James Salinger.

K.-W. Lan · M.-A. Lee $(\bowtie)$

Department of Environmental Biology and Fisheries Science, National Taiwan Ocean University,

2 Pei-Ning Rd., Keelung 20224 Taiwan, Republic of China

e-mail: malee@mail.ntou.edu.tw

K. Evans

Wealth from Oceans National Research Flagship, CSIRO Marine and Atmospheric Research, GPO Box 1538, Hobart, Tasmania 7001, Australia

M.-A. Lee

Center of Excellence for Marine Bioenvironment and Biotechnology, Keelung 20224 Taiwan,

Republic of China 


\section{Introduction}

Climatic oscillations, anomalies, and changes clearly affect many ecological processes in marine ecosystems, affecting the population abundances and distributions of many species (Sharp 1992; Stenseth et al. 2004; Tian et al. 2008). Variations in population abundances and distributions of pelagic tuna species have been observed to be clearly linked to large-scale climate phenomena such as the El Niño Southern Oscillation (ENSO) in the Pacific Ocean (Lehodey et al. 1997; Sugimoto et al. 2001; Torres-Orozco et al. 2006) and the North Atlantic Oscillation in the Atlantic Ocean (Santiago 1997; Lan et al. 2011).

In the Pacific Ocean, El Niño events are associated with a weakening of the equatorial trade winds and in association, the major currents in the basin, resulting in an easterly shift in the equatorial warm pool region. Upwelling associated with the Pacific Equatorial Divergence (PEQD) decreases, resulting in a deepening of the thermocline in the central and eastern regions of the Pacific and becomes shallower in the west. Stronger wind stresses in the western Pacific result in an increase in productivity in this region (Trenberth 1991; Folland et al. 2002; McPhaden 2004). As a result, the distribution of warm water species of tuna such as yellowfin (Thunnus albacares) and skipjack tuna (Katsuwonus pelamis) expands into central and eastern regions of the Pacific, increasing their exposure to fisheries in this region. In addition, the depth at which yellowfin tuna have access to abundant food compresses with the shallowing of the thermocline in the west, resulting in increased vulnerability of this species to surface fisheries in this region (Lehodey et al. 1997, 1998; Lehodey 2004). During La Niña, the opposite occurs with stronger trade winds pushing the warm pool region to the west and deepening the thermocline, while the PEQD increases resulting in a shallower thermocline in the central and eastern Pacific. Distributions of yellowfin and skipjack tuna are pushed further to the west and the vertical habitat of yellowfin tuna is expanded, reducing the vulnerability of the species to surface fisheries in the region (Lehodey et al. 1997, 1998; Lehodey 2004).

Large-scale climate fluctuations also occur in the Indian Ocean driven by patterns of inter-annual variability in sea-surface and subsurface temperatures which result in changes in accompanying wind and precipitation anomalies (Saji et al. 1999). This ocean-atmosphere phenomenon, known as the Indian Ocean Dipole (IOD) is in a positive phase when an anomalous upwelling occurs along the Sumatra-Java coast, enhancing cooling of sea surface temperatures (SSTs) in the eastern Indian Ocean. This cooling couples with a westward wind anomaly along the equator, resulting in a deepening of the thermocline and warmer SSTs in the western Indian Ocean. The shift in trade winds results in decreased convection over the oceanic tropical convergence zone (OTCZ), encouraging increased rainfall to the northwest of the OTCZ and reduced wind speed and decreased rainfall in the east (Saji et al. 1999; Feng and Meyers 2003; Meyers et al. 2007). As a result of warmer SSTs and a deeper thermocline in the west, surface primary productivity decreases in the west and increases in the east in association with upwelling and a shallower thermocline (Marsac 2008). Some positive IOD events coincide with El Niño and similarly some negative IOD events coincide with La Niña events, resulting in the strongest SST anomalies (Yamagata et al. 2004), however, not all IOD events co-occur with ENSO events (Meyers et al. 2007).

Yellowfin tuna constitute one of the major targets of industrialised fisheries in the Indian Ocean and are predominantly caught by purse seine, and longline fisheries, with smaller catches also taken by gillnet, handline and pole and line fisheries (IOTC 2009). Catches of yellowfin tuna were predominantly caught by Japanese, Taiwanese and Korean longline fleets until the early 1980s, when purse seine fishing using FADs was developed by French and Spanish vessels and Iranian and Sri Lankan gillnet fisheries were expanded (Miyake et 
al. 2004). More recently, catch rates have dropped from peak catches recorded in 2006 due to a reduction in the purse seine fleet, and also it is thought, due to the expansion of piracy in core fishing areas for the longline fleet (IOTC 2011). Longline catch rates suggest that yellowfin tuna are distributed in tropical waters throughout the entire Indian Ocean with no clear stock boundaries known. Catches are primarily concentrated western tropical waters, the Arabian Sea and north of the Mozambique Channel (Marsac 2001; IOTC 2011; Lan et al. 2012a, b).

Shifts in the distribution of catches and catch rates of yellowfin tuna by the purse seine fleet in the Indian Ocean have been associated with positive IOD events (Marsac and LeBlanc 2000; Menard et al. 2007; Marsac 2008; Lan et al. 2012a). During a positive IOD event in 1997-98, catch rates declined in the western Indian Ocean in association with a deepening of the thermocline and a reduction in surface biological productivity, which resulted in a reduction in surface schools available to the fishery. At the same time concentrations of surface schools increased to the east in association with an anomalous shallow thermocline (Marsac and LeBlanc 2000; Marsac 2008). However, the relationship between yellowfin tuna catches and the IOD is not entirely clear; during a positive IOD event in 2006-07, similar declines in catches were observed in the western Indian Ocean, but without a corresponding shift of the fleet to the east (Marsac 2008).

There is therefore a need to better understand the relationships between the IOD and catch rates of yellowfin tuna in the Indian Ocean and the underlying processes associated with variability in catch rates. The purpose of this study was to firstly investigate long-term time series of IOD events and catch rates of YFT in the longline fishery in the western Indian Ocean to determine potential relationships over multi-decadal time scales. Secondly, finescale relationships between SST and estimated primary productivity and catch rates were investigated to explore the underlying processes influencing yellowfin tuna catch rates and distributions in the western Indian Ocean. Longline catches were used because of the long time period of catch data available for the fishery (1970-2008) and data are publically available from the Indian Ocean Tuna Commission website (www.iotc.org).

\section{Materials and methods}

\subsection{YFT fishery data}

\subsubsection{Long-term longline fishery catch data}

Long-term longline fishery catch data in the Indian Ocean from January 1970 to December 2008 were obtained from the Indian Ocean Tuna Commission (IOTC) website (http:// www.iotc.org). These data were derived from data submitted by a number of nations to the IOTC and include both catch (species by number or weight depending on the fleet) and operational data (number of hooks and area coordinates). Because more than $95 \%$ of longline effort in the Indian Ocean is expressed as number of individuals caught, we only included catch in numbers here. Monthly nominal CPUE was calculated as the number of individuals captured per 1000 hooks (fish $/ 10^{3}$ hooks).

\subsubsection{High spatial resolution longline catch data}

High spatial resolution longline catch data for the period from January 2002-December 2008 were provided by the Overseas Fisheries Development Council of Taiwan. These data comprise daily geo-referenced fishing positions (latitude and longitude), species number and 
weight, and fishing effort (number of hooks). Monthly nominal CPUE was calculated as the number of individuals captured per 1000 hooks.

\subsection{Climatic index and environmental data}

The growth and maintenance of positive and negative anomalies associated with the IOD are represented by the Dipole Modular Index (DMI), which is constructed from monthly differences between SST anomalies in the western equatorial $\left(50^{\circ} \mathrm{E}-70^{\circ} \mathrm{E}, 10^{\circ} \mathrm{S}-10^{\circ} \mathrm{N}\right)$ and southeastern equatorial $\left(90^{\circ} \mathrm{E}-110^{\circ} \mathrm{E}, 10 \mathrm{~S}^{\circ}-0^{\circ} \mathrm{N}\right)$ Indian Ocean (Saji et al. 1999). We used a monthly time series of the standard DMI index derived from the HadISST dataset of 1970-2008 (http://www.jamstec.go.jp/frcgc/research/d1/iod/) to identify positive and negative IOD events. The time series of DMI was detrended and constructed using the reduced space optimal interpolation technique (Kaplan et al. 1997).

SST pathfinder monthly composites fields with a $4 \mathrm{~km}$ spatial resolution during the period of 2002-2008 were obtained from the National Oceanographic Data Center (http:// www.nodc.noaa.gov/). Net primary productivity (NPP) monthly estimates with $9 \mathrm{~km}$ resolution were obtained from the Oregon State University's Ocean Productivity Web site (http:// www.science.oregonstate.edu/ocean.productivity/) for the period January 2002-December 2008. These estimates are based on the Vertically Generalized Production Model (VGPM) developed by Behrenfeld and Falkowski (1997), which is the standard algorithm for NPP estimation.

\subsection{Standardization of nominal CPUE}

Nominal CPUE values for both fishery datasets were standardized using a Generalized Linear Model (GLM) constructed in R (version 2.15.0) software. The main effects considered were temporal (year, month), spatial (longitude, latitude,) and targeting of the fleet (CPUE of bigeye tuna, CPUE of albacore), and the interactions of the main effects were also included in the model:

$$
\begin{aligned}
\log (C P U E+c)= & \mu+\text { Year }+ \text { Month }+ \text { Latitude }+ \text { Longitude }+ \text { CPUE }(\text { bigeye }) \\
& + \text { CPUE }(\text { albacore })+\text { Interactions }+\varepsilon
\end{aligned}
$$

where CPUE is the nominal CPUE of yellowfin tuna, $\mu$ is the intercept, and $\varepsilon$ is a normally distributed variable with a mean equal to zero. To account for zero catch values in the data, we added 0.1 fish per 1000 hooks to CPUE values $(c)$. The model selection process for standardizing CPUE was done in a forward stepwise procedure (Table 1). The model with the best fit was selected using the lowest Akaike information criterion (AIC). We were unable to account for potential changes in targeting methods (e.g. gear configurations) as these details were not available for the dataset used.

\subsection{Longitudinal gravitational centre of the long-term fishery data}

In order to better understand the spatial distribution of the fishery and variability associated, the longitudinal gravitational center of standardized CPUE $(G)$ was estimated by the monthly longitudinal location of fishing vessels $(L)$ and standardized CPUE (Lehodey et al. 1997):

$$
G_{i}=\frac{\sum L_{i} \times C P U E_{i}}{\sum C P U E_{i}}
$$


Table 1 Construction of the GLM, the residual deviance, the approximate AIC, and $p$ values

\begin{tabular}{|c|c|c|c|c|}
\hline & Residual d.f. & Residual deviance & AIC & $p$ value \\
\hline NULL & 65430 & 14116.52 & 11566.50 & \\
\hline$+\mathrm{s}($ Year $)$ & 65429 & 11511.69 & 11512.40 & $<0.01$ \\
\hline$+\mathrm{s}$ (Month) & 65428 & 11469.00 & 11470.05 & $<0.01$ \\
\hline$+\mathrm{s}(\mathrm{Lat})$ & 65427 & 10072.28 & 10073.51 & $<0.01$ \\
\hline$+\mathrm{s}($ Lon $)$ & 65426 & 9416.54 & 9417.98 & $<0.01$ \\
\hline +s(bigeye CPUE) & 65425 & 9358.54 & 9360.26 & $<0.01$ \\
\hline+ s(albacore CPUE) & 65424 & 9357.42 & 9359.42 & $<0.01$ \\
\hline +s(Year, Month) & 65423 & 9356.59 & 9358.88 & $<0.01$ \\
\hline$+\mathrm{s}$ (Year, Lat) & 65422 & 9316.64 & 9316.64 & $<0.01$ \\
\hline +s(Year, Lon) & 65421 & 9210.70 & 9213.14 & $<0.01$ \\
\hline +s(Lat, Lon) & 65421 & 8830.08 & 8861.72 & $<0.01$ \\
\hline
\end{tabular}

\subsection{Time series analysis of the long-term fishery data with DMI}

Time series analyses are valuable tools for investigating long-term fluctuations in fish catch rates and relationships between catch rates and environmental variables. In order to account for seasonality in the DMI, we employed a state-space structural decomposition approach using MATLAB software. By so doing, a time series of DMI is decomposed into seasonal, cyclical and irregular components (Casals et al. 2002). As we were interested in inter-annual variability, we used only the trend-cycle component in the correlation, regression, and wavelet analyses.

Wavelet analysis was used to investigate relationships between the DMI and yellowfin tuna catch rates. Wavelet analysis is a common tool for analyzing time-series data and involves decomposing a time series in a time-frequency space, allowing identification of the dominant periodic components and how these components vary in time (Torrence and Compo 1998). The Morlet wavelet is the most popular complex wavelet used in practice, and is defined as:

$$
\psi_{0}(\eta)=\pi^{-1 / 4} e^{i \varpi o} e^{-\eta^{2} / 2}
$$

where $\eta$ is a dimensionless time parameter and $\omega_{0}$ is a dimensionless frequency taken to balance between the time and frequency localization. The $95 \%$ significance level was determined based on bootstrap simulations taken as a first-order autoregressive process. The autoregression coefficient was empirically obtained from the time series data. Crosswavelet coherence (Grinsted et al. 2004) and phase analyses were then used to investigate causal relationships between the DMI and catch rates. Free MATLAB software to carry out this decomposition is available from the $\mathrm{E}^{4}$ team (http://www.ucm.es/info/icae/e4/).

\subsection{Statistical models for spatial predictions of high spatial resolution fishery data}

We used Generalized Additive Models (GAMs) to predict spatial patterns of potential yellowfin tuna habitat from relationships determined between SSTs, NPP and fine-scale longline catches. GAMs were constructed in $\mathrm{R}$ (version 2.15.0) software, using the gam function of the mgcv package (Wood 2006), with standardized CPUE as the response variable with year, month, longitude, latitude, SST, NPP and DMI as predictor variables. 
The GAM can be written as:

$$
\log (\mathrm{CPUE}+c)=a_{0}+\mathrm{s}_{1}\left(\mathrm{x}_{1 \mathrm{i}}\right)+\mathrm{s}_{2}\left(\mathrm{x}_{2 \mathrm{i}}\right)+\mathrm{s}_{3}\left(\mathrm{x}_{3 \mathrm{i}}\right)+\ldots \mathrm{s}_{\mathrm{n}}\left(\mathrm{x}_{\mathrm{ni}}\right) ;
$$

where CPUE is the CPUE of the high spatial resolution longline catch data, $a_{0}$ is the model constant, and $s_{n}$ is a smoothing function for each of the model covariates $x_{n}$ (Wood 2006). To account for zero catch values in the data, we added 0.1 fish per 1000 hooks to CPUE values $(c)$.

The model with the best fit was selected using a stepwise procedure and based on the lowest the residual deviance and AIC. The selected GAM models were then used to estimate the relative density of yellowfin tuna across the Indian Ocean under varying SST, NPP and IOD events.

\section{Results}

3.1 Temporal variations and spatial distributions of yellowfin tuna CPUE and the longitudinal gravity centre

Standardized CPUE during the period 1970-2008 varied 4.57-5.96 fish/10 $0^{3}$ hooks in the first half of the year (January to June) during positive IOD events (Fig. 1d) to 5.86 to 7.91 fish $/ 10^{3}$ hooks during negative events. Increases in CPUE occurred in particular in the Arabian Sea and regions around Madagascar (Fig. 1b).

\section{a}
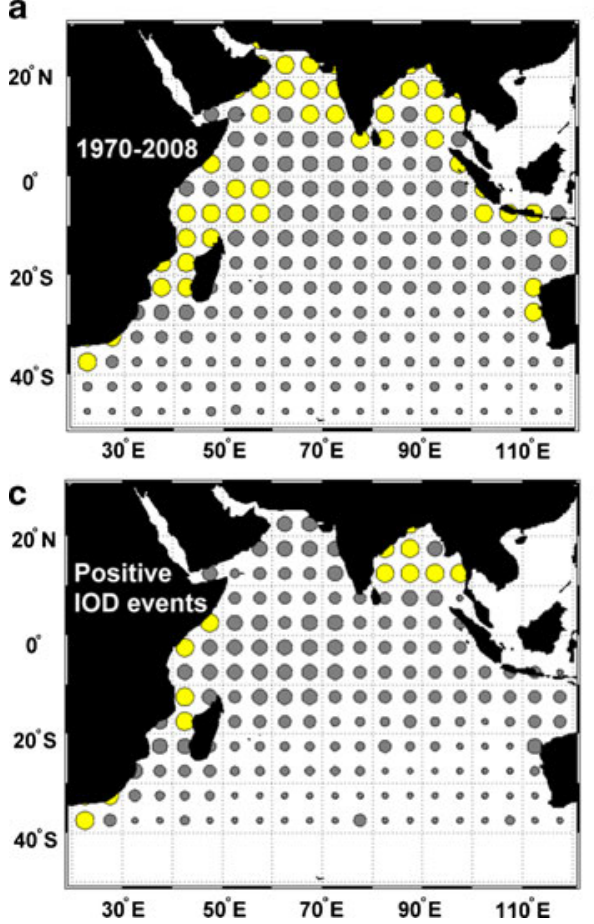

b

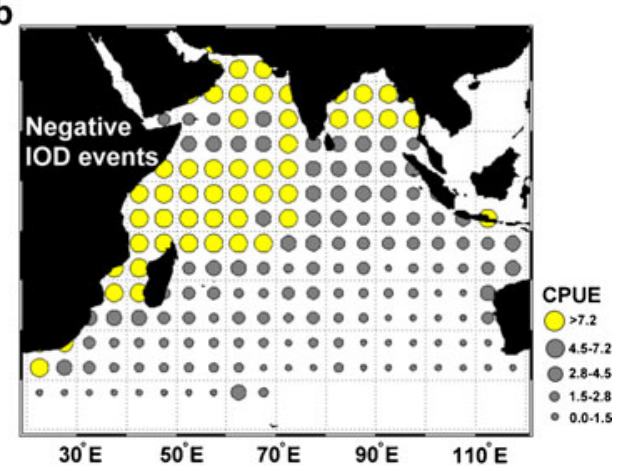

d

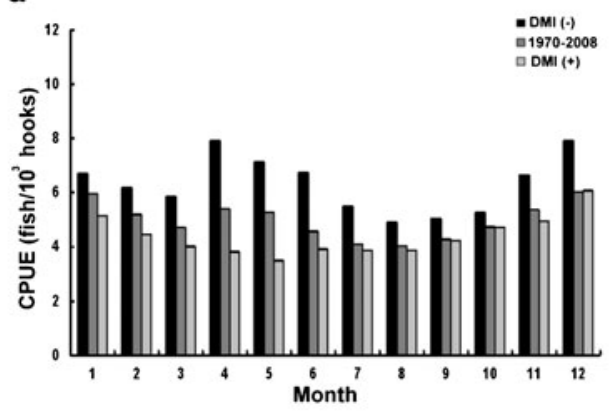

Fig. 1 Spatial distribution of standardized CPUE of yellowfin tuna a 1970-2008, during b positive and c negative IOD events and. d monthly standardized CPUE of yellowfin tuna 1970-2008 (grey), during positive (white) and negative (black) IOD events 
The longitudinal gravitational centre of standardized CPUE (G) varied considerably on an inter-annual basis and at similar amplitude to the DMI (Fig. 2). During positive IOD events, such as in 1991, 1995 and 2007, the fleet extended its activities to as far east as $70^{\circ} \mathrm{E}$ in the first half year, but moved west to $50^{\circ} \mathrm{E}$ during negative events (1992, 1996, and 2004-2006).

\subsection{Time series analysis}

Spatial distributions of standardized CPUE (Fig. 1a) showed that high CPUE values were mainly concentrated in the west and the north Indian Ocean $\left(30^{\circ} \mathrm{N}-25^{\circ} \mathrm{S}, 40^{\circ} \mathrm{E}-\right.$ $\left.60^{\circ} \mathrm{E}\right)$, and expanded into to the east $\left(30^{\circ} \mathrm{N}-25^{\circ} \mathrm{S}, 40^{\circ} \mathrm{E}-80^{\circ} \mathrm{E}\right)$ during negative IOD events (Fig. 1b). Given that most of the variability in CPUE occurred in the region of $30^{\circ} \mathrm{N}-25^{\circ} \mathrm{S}, 40^{\circ} \mathrm{E}-80^{\circ} \mathrm{E}$, we restricted further investigations of relationships between the DMI and yellowfin tuna catch rates to this region. Using a state-space time series analysis, a single decomposition procedure effectively removed seasonality from the time series data of the DMI dataset (Fig. 3a). Wavelet analysis identified a significant negative correlation between standardized CPUE and the DMI with periodicities centred around 4 years (Fig. 3b), suggesting that during positive IOD events standardized CPUE is reduced and during negative IOD events standardized CPUE increases.

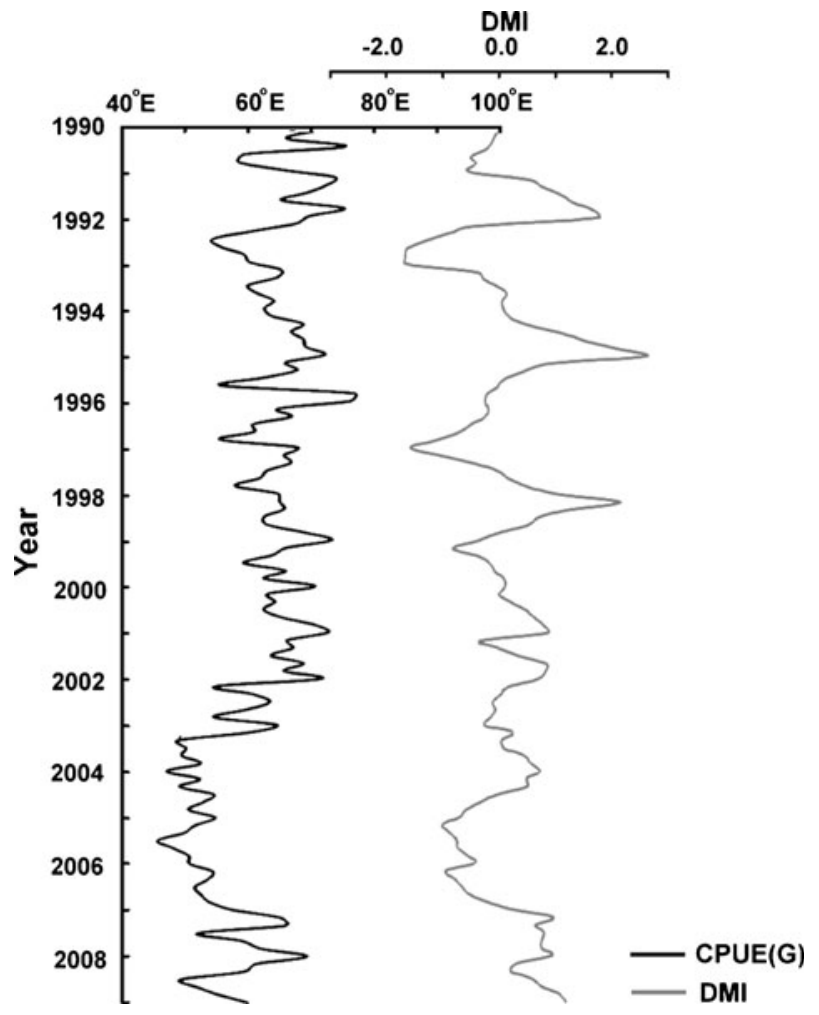

Fig. 2 Longitudinal gravitational center of standardized CPUE of yellowfin tuna (black) and the DMI (gray) during January to June in the Indian Ocean in 1990-2008 


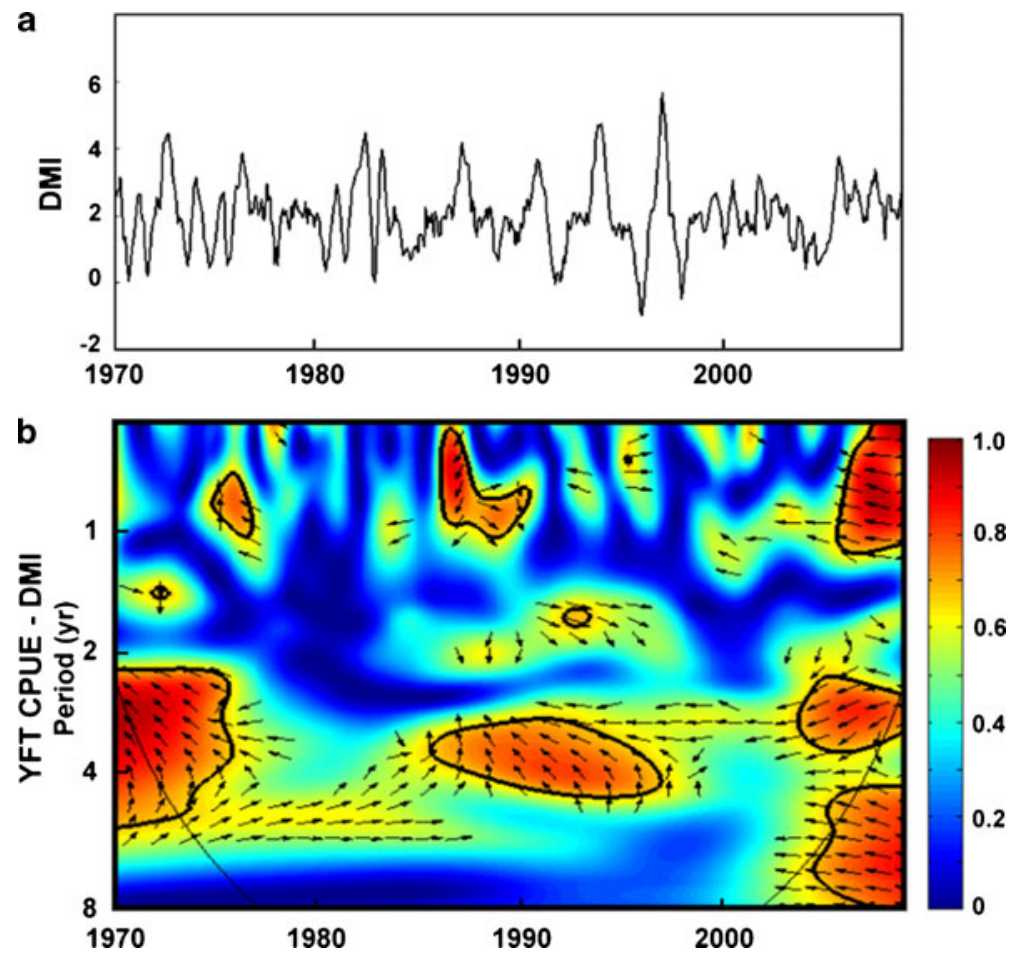

Fig. 3 Time series of a the Dipole Mode Index (DMI). Values are normalized to the unit mean and variance. b Cross-wavelet coherence between standardized CPUE and the DMI 1970-2008. The solid-black contour encloses regions of $>95 \%$ confidence, and the black line indicates where edge effects become important, high variability is represented by red, and weak variability by blue. Arrows indicate the phase relationship with inphase arrows pointing to the right and out-of-phase arrows pointing to the left

\subsection{Projected changes in environmental conditions of the fishing grounds}

Comparisons of mean SSTs and NPP between a positive (2007) and a negative (2004) IOD event (Fig. 4) demonstrated that in 2007, higher SSTs $\left(>29^{\circ} \mathrm{C}\right)$ extended across most of the northern Indian Ocean, whilst during 2004 high SSTs occurred in the central and eastern equatorial Indian Ocean and Gulf areas in the northwest. Cold water intrusions along eastern African which occurred in 2004 were absent in 2007 (Fig. 4a, b). During 2007, NPP $>300 \mathrm{mg} \mathrm{C} / \mathrm{m}^{2} / \mathrm{d}$ was largely restricted to regions in the northern Indian Ocean, while in 2004, areas of high NPP extended into equatorial regions to the south and west (Fig. 4c, d).

All variables included in the GAM selection process were significant $(p<0.01)$ (Table 2). The cumulative deviance explained by the selected GAM model was 38.6. Almost half of the explained deviance was associated with longitude and DMI, resulting in the largest change in AIC values. Values of CPUE increased in the western Indian Ocean at $40^{\circ} \mathrm{E}-75^{\circ} \mathrm{E}$ during negative IOD events (Fig. 5a, d) and was associated with SSTs of 26-29.5 ${ }^{\circ} \mathrm{C}$ and NPP of 220-380 mg C/m²/d (Fig. 5b, c).

Spatial distributions of SST and NPP values identified in the GAM indicate that potential fishing grounds with high CPUE values occurred in the Arabian Sea, central Indian Ocean, and regions around Madagascar in during the negative IOD event in 2004 (Fig. 6a). During 

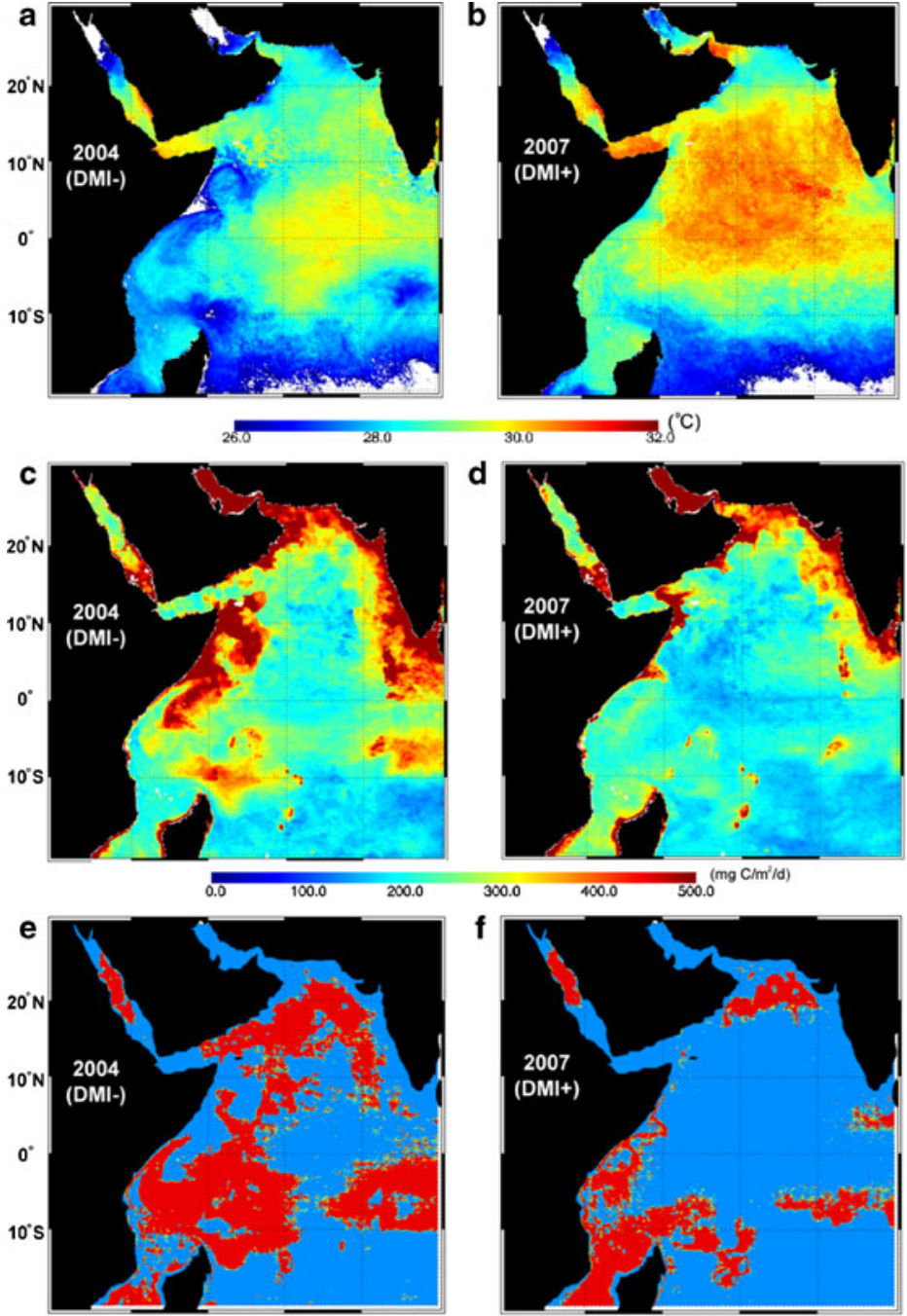

Optimal areas (SST 26-29.5 C and NPP 220-380 mg C/m²/d)
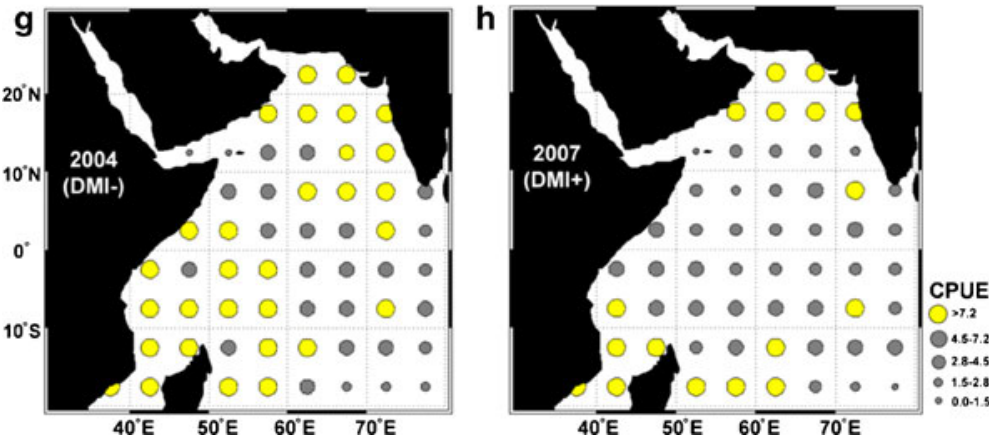

Fig. 4 Composite averages of $\mathbf{a}, \mathbf{b}$ SST and $\mathbf{c}, \mathbf{d}$ NPP, e, $\mathbf{f}$ predicted optimal habitat for yellowfin tuna based on SST $\left(26-29.5^{\circ} \mathrm{C}\right)$ and NPP $\left(220-380 \mathrm{mg} \mathrm{C} / \mathrm{m}^{2} / \mathrm{d}\right)$ and $\mathbf{g}$, $\mathbf{h}$ spatial distributions of average standardized CPUE during January to June in a positive (2007) and negative (2004) Indian Ocean Dipole event 
Table 2 Residual deviance, cumulative variance, and AIC of CPUE values of high-spatial-resolution longline catch data explained in a GAM with variables sequentially added (first to last)

\begin{tabular}{|c|c|c|c|c|}
\hline & Residual deviance & Cumulative variance & AIC & $p$ value \\
\hline NULL & 558.73 & & 558.22 & \\
\hline Year & 552.29 & 3.71 & 553.13 & $<0.01$ \\
\hline Month & 549.34 & 11.80 & 550.57 & $<0.01$ \\
\hline Latitude & 547.12 & 26.90 & 548.76 & $<0.01$ \\
\hline Longitude & 454.35 & 32.30 & 454.04 & $<0.01$ \\
\hline SST & 450.93 & 35.40 & 454.03 & $<0.01$ \\
\hline NPP & 445.15 & 36.00 & 447.17 & $<0.01$ \\
\hline DMI & 418.26 & 38.60 & 420.88 & $<0.01$ \\
\hline
\end{tabular}

the positive IOD event in 2007 the spatial distribution of potential fishing grounds were more concentrated around western Madagascar (Fig. 6b)

\section{Discussion}

The results of this study show that temporal and spatial distributions of yellowfin tuna longline catches are linked to climatic oscillations in the Indian Ocean of periodicities centred around 4 years. Catch rates increased in association with decreases in SSTs and
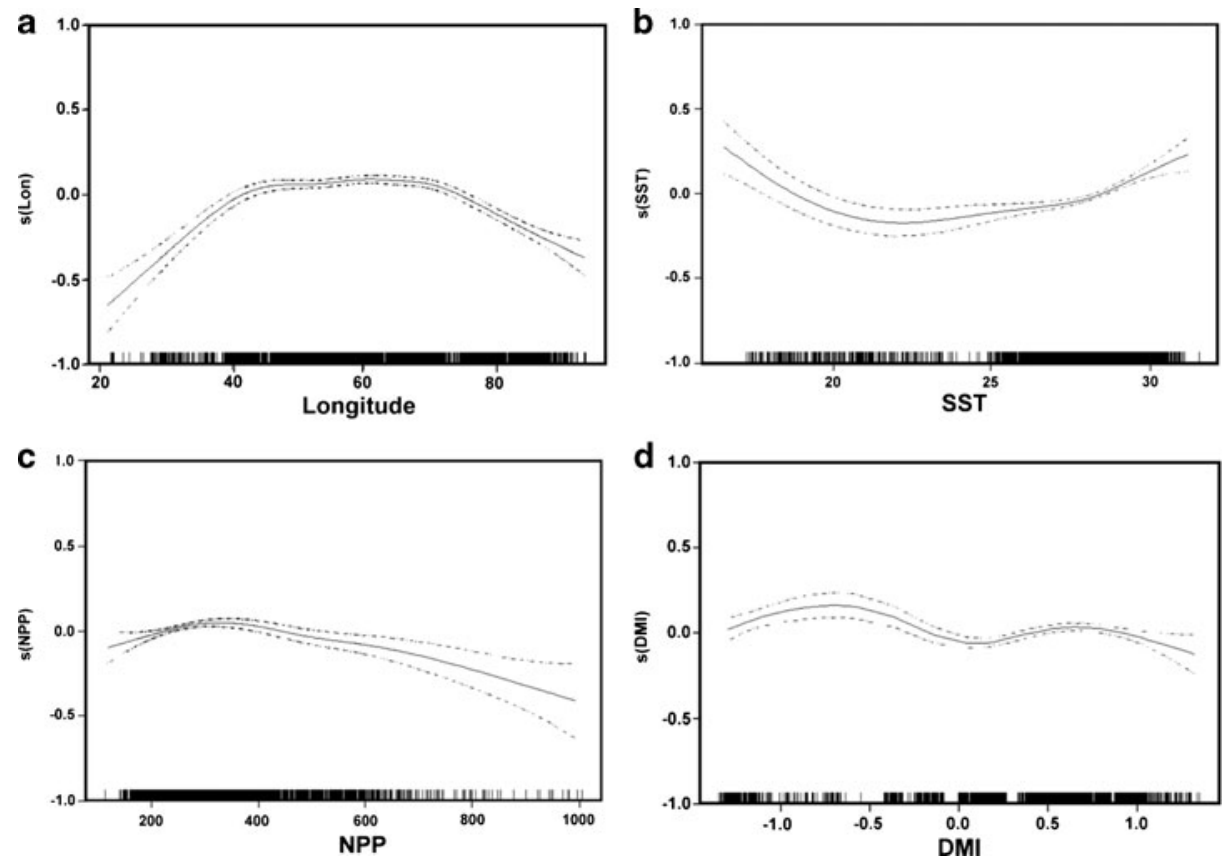

Fig. 5 Modelled effect of a longitude, b SST, c NPP, and d DMI on CPUE. The solid line shows the fitted GAM function and the black-dotted line indicates $95 \%$ confidence intervals. Relative density of data points are indicated by the rug plot on the $\mathrm{x}$-axis 


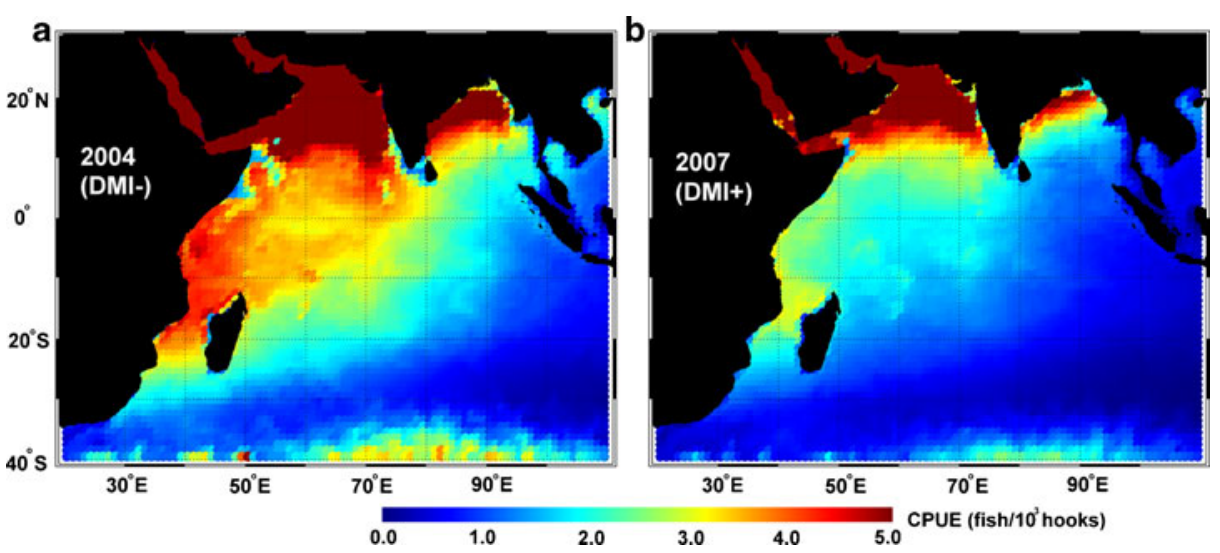

Fig. 6 Predicted yellowfin tuna CPUE in the second quarter (March to June) in a negative (2004) and b positive (2007) Indian Ocean Dipole event

increases in NPP during negative IOD events from January to June in the western Indian Ocean and decreased in association with increases in SSTs and decreases in NPP during positive IOD events. Catch rates of yellowfin tuna in the purse seine fishery have also been observed to increase (decrease) with negative (positive) IOD events (Marsac and LeBlanc 2000; Menard et al. 2007; Marsac 2008) and suggest that variations in catches observed in this study are consistent across fisheries for yellowfin tuna in the western Indian Ocean.

Warm and cold events in the western Indian Ocean induced by the IOD drive changes in the marine environment such as primary production and the mixed-layer depth with consequences for tuna abundances (Corbineau et al. 2008; Marsac 2008). The cool, steady, and strong southwestern monsoon associated with negative IOD events generates extensive coastal upwelling over the margin of continental areas in the northwestern Indian Ocean, driving an increase in primary production which would be expected to have flow-on effects on higher order productivity in the region (Menard et al. 2007; Corbineau et al. 2008). The shallowing of the thermocline, restricts the vertical distribution of enhanced productivity to surface layers (Murtugudde et al. 1999; Marsac 2008). During positive IOD events, shifting trade winds increase convergence in the west reducing wind speeds and convection resulting in a general warming of surface temperature, a reduction of coastal upwelling and lower productivity. The deepening of the thermocline further disperses productivity into subsurface layers (Saji et al. 1999; Marsac 2008). In the 2007 positive IOD event, water temperatures were relatively high $\left(>29.5^{\circ} \mathrm{C}\right)$ in areas with low NPP $\left(<220 \mathrm{mg} \mathrm{C} / \mathrm{m}^{2} / \mathrm{d}\right)$ in the western Indian Ocean, including the southern Arabian Sea and the entire central Indian Ocean. During the 1997-98 positive IOD event primary productivity decreased on the order of $30 \%$ in the northwestern Indian Ocean, largely due to reduced vertical mixing and a lower flux of nutrients into surface layers as a result of the deepening of the thermocline (Sarma 2006).

Our results suggest that high catch rates of yellowfin tuna are associated with the SSTs of $26-29.5^{\circ} \mathrm{C}$ in the Indian Ocean and NPP of $220-380 \mathrm{mg} \mathrm{C} / \mathrm{m}^{2} / \mathrm{d}$. High catches mostly did not occur in areas with the highest NPP values, but more so in areas with stable NPP values, suggesting that shifts in the distribution of the longline fleet might be more highly influenced by thermal habitat rather than productivity per se. The short temporal response of yellowfin longline catches to changes in the IOD also suggests that habitat variability may contribute to distributions and therefore catches of yellowfin more so than productivity (Menard et al. 2007). 
Yellowfin tuna occur primarily in waters where surface temperatures range $20-30{ }^{\circ} \mathrm{C}$, although have been observed to occur in waters down to $15^{\circ} \mathrm{C}$ in low numbers (Sund et al. 1981). Similar water temperatures limit their vertical distribution, with fish predominantly distributed in the upper $200 \mathrm{~m}$ of the water column (Sund et al. 1981; Block et al. 1997; Brill et al. 1999; Schaefer et al. 2007). Temperature appears to dictate the distribution of yellowfin tuna in all regions except the eastern Pacific Ocean (EPO) where both temperature and oxygen concentrations contribute to form a cold hypoxic environment, restricting the distribution of most tunas and billfish (Prince and Goodyear 2006). Changes in the vertical distribution of available habitat to yellowfin tuna associated with ENSO have been observed to influence the availability of individuals to fisheries in the Pacific Ocean (Lehodey et al. 2011). During El Niño, as the depth of the thermocline deepens and the available vertical habitat for yellowfin increases, the availability of fish to fisheries decreases. The revese occurs during La Niña as the thermocline shoals and the available habitat for yellowfin tuna compresses, resulting in increased vulnerability of individuals to surface fisheries (Lehodey et al. 2011). It is likely that similar changes in the depth of the thermal habitat available to yellowfin tuna are driving changes in catches in the western Indian Ocean in association with IOD events. As the thermocline shoals and increased productivity is limited to surface waters during negative IOD events, the depth at which yellowfin tuna have access to abundant food and thermal habitat compresses, increasing their susceptibility to fisheries. Then as thermal habitat increases both horizontally and vertically and surface productivity decreases during positive IOD events yellowfin tuna disperse reducing their availability to fisheries in the region (Menard et al. 2007; Marsac 2008).

Interestingly, shifts in the gravitational center during very weak positive IOD events (1999 2001) were observed to be on the order of those occurring during very strong positive IOD events (1997 1999). This suggests that there may be other factors influencing the spatial distribution of the CPUE including changing fleet dynamics and further unknown and complex changes in the physical and biological systems of the Indian Ocean not investigated here. Further investigations including in particular fishing gear configurations and targeting strategies (where available) will provide further insights into factors influencing the spatial distribution of CPUE in the Indian Ocean.

\section{Conclusions and remarks}

Using longline fishery and marine environmental data, we found that distributions and catches of YFT were sensitive to climatic and marine environmental variations in the Indian Ocean. A significant negative coherence between the DMI and CPUE values with a periodicity centred around 4 years was observed. Our results suggest that high SST $\left(>29.5^{\circ} \mathrm{C}\right)$ combined with low $\operatorname{NPP}\left(<220 \mathrm{mg} \mathrm{C} / \mathrm{m}^{2} / \mathrm{d}\right)$ during positive IOD events are associated with decreased CPUE in the western Indian Ocean, whereas lower SST and high NPP are associated with increased CPUE in negative IOD events, especially in the Arabian Sea and around Madagascar.

This study provides preliminary insights into some of the key environmental features driving the distribution of yellowfin tuna in the western Indian Ocean and associated variability in fisheries catches. However, there are still gaps in understanding the processes associated with IOD events driving the distribution of yellowfin, particularly in terms of changes in productivity of the western equatorial Indian Ocean, and connections with areas outside of the western equatorial Indian Ocean. Similarly, what effect IOD events might have on spawning migration and recruitment throughout the region are unknown. What impact lagged processes, particularly biological lags might have on tuna populations and 
associated catches are largely unexplored. In addition, fluctuations in tuna populations might not simply be determined by any single environmental factor, but rather might be influenced by non-linear combinations of several factors including changes in fishing effort, targeting practices and fleet dynamics (Hsieh et al. 2008). Including aspects of fishing behaviour will be an important next step in conducting more comprehensive investigations into the influence of climate variability on tuna fisheries. Finally, the associations between SST and NPP and catch rates presented here are qualitative and only based on single comparisons. The time series of fine scale longline fishing data (6 years) and the periodicity that the IOD occurs at ( $\sim 4$ years) means that relationship cannot be explored further and quantified. As a result, it is not clear that patterns and relationships observed are consistent across the IOD cycle. Longer time series will be crucial for exploring the robustness of relationships identified here.

Acknowledgements This study was financially supported by the Council of Agriculture (99AS-10.1.1-FAF6(3) and 100AS-10.1.2-FA-F1) and the National Science Council (NSC 100-2621-M-019-001). We are grateful to the Oversea Fisheries Development Council (OFDC) of Taiwan for providing data from the Taiwanese longline fishery. The first author especially thanks the conveners of the International Workshop on Climate and Ocean Fisheries for inviting him to present material and the Asia-Pacific Network for Global Change Research for supporting his attendance at the workshop. Issues discussed in this paper are motivated in part by the CLIOTOP program. I. M. Belkin of University of Rhode Island and an anonymous reviewer kindly helped revise the manuscript.

Open Access This article is distributed under the terms of the Creative Commons Attribution License which permits any use, distribution, and reproduction in any medium, provided the original author(s) and the source are credited.

\section{References}

Behrenfeld MJ, Falkowski PG (1997) Photosynthetic rates derived from satellite-based chlorophyll concentration. Limnol Oceanogr 42:1-20

Block BA, Keen JA, Castillo B, Dewar H, Freund EV, Marcinek DJ, Brill RW, Farwell C (1997) Environmental preferences of yellowfin tuna (Thunnus albacares) at the northern extent of its range. Mar Biol 130:119-132

Brill RW, Block BA, Boggs CH, Bigelow KA, Feund EV, Marcinek DJ (1999) Horizontal movements and depth distribution of large adult yellowfin tuna (Thunnus albacares) near the Hawaiian Islands, recorded using ultrasonic telemetry: implications for the physiological ecology of pelagic fishes. Mar Biol 133:395-408

Casals J, Jerez M, Sotoca S (2002) An exact multivariate model-based structural. J Am Stat Assoc 97 (458):553-564

Corbineau A, Rouyer T, Cazelles B, Fromentin JM, Fonteneau A, Menard F (2008) Time series analysis of tuna and swordfish catches and climate variability in the Indian Ocean (1968-2003). Aquat Living Resour 21:277-285

Feng M, Meyers G (2003) Interannual variability in the tropical Indian Ocean: a two-year time scale of IOD. Deep-Sea Res II 50:2263-2284

Folland CK, Renwick JA, Salinger MJ, Ab M (2002) Relative influences of the Interdecadal Pacific Oscillation and ENSO on the South Pacific Convergence Zone. Geophys Res Lett 29:1643. doi:10.1029/2001GL014201

Grinsted A, Moore JC, Jeverejeva S (2004) Application of the cross wavelet transform and wavelet coherence to geophysical time series. Nonlinear Process Geophys 11:561-566

Hsieh CH, Anderson C, Sugihara G (2008) Extending nonlinear analysis to short ecological time series. Am Nat 17:71-80

IOTC (2009) Report of the Twelfth Session of the Scientific Committee of the Indian Ocean Tuna Commsion. Victoria, Seychelles, $190 \mathrm{pp}$

IOTC (2011) Executive summary: status of the Indian Ocean yellowfin (Thunnus albacares) resource. Paper IOTC-2011-SC14-11 prepared for the fourteenth session of the Scientific Committee of the Indidian Ocean Tuna Commission. 
Kaplan A, Kushnir Y, Cane M, Blumenthal (1997) Reduced space optimal analysis for historical data sets: 136 years of Atlantic sea surface temperature. J Geophys Res 102:27835-27860

Lan KW, Lee MA, Lu HJ, Shieh WJ, Lin WK, Kao SC (2011) Ocean variations associated with fishing conditions of yellowfin tuna (Thunnus albacares) in the equatorial Atlantic Ocean. ICES J Mar Sci 68(6):1063-1071

Lan KW, Lee MA, Nishida T, Lu HJ, Weng JS, Chang Y (2012a) Environmental effects on yellowfin tuna catch by the Taiwan longline fishery in the Arabian Sea. Int J Remote Sens 33(23):7491-7506

Lan KW, Nishida T, Lee MA, Lu HJ, Huang HW, Chang SK, Lan YC (2012b) Influence of the marine environment variability of the yellowfin tuna (Thunnus albacares) catch rate by the Taiwanese longline fishery in the Arabian Sea, with special reference to the high catch in 2004. J Mar Sci Tech 20(5):514-524

Lehodey P, Bertignac M, Hampton J, Lewis A, Picaut J (1997) El Niño Southern Oscillation and tuna in the western Pacific. Nature 389:715-718

Lehodey P, Andre JM, Bertignac M et al (1998) Predicting skipjack tuna forage distributions in the equatorial Pacific using a coupled dynamical bio-geochemical model. Fish Oceanogr 7:317-325

Lehodey P (2004) Climate and fisheries: an insight from the Pacific Ocean. In: Stenseth NC, Ottersen G, Hurrel J, Belgrano A (eds) Ecological effects of climate variations in the North Atlantic. Oxford University Press, Oxford, pp 137-146

Lehodey P, Hampton J, Brill RW, Nicol S, Senina I, Calmettes B, Pørtner HO, Bopp L, Ilyina T, Bell JD, Sibert J (2011) In: Bell JD, Johnson JE, Hobday AJ (eds) Vulnerability of tropical Pacific fisheries and aquaculture to climate change. Secretariat of the Pacific Community, Noumea, pp 433-492

Marsac F (2001) Climate and oceanographic indices appraising the environmental fluctuations in the Indian Ocean. IOTC Proc 4:293-301

Marsac F (2008) Outlook of ocean climate variability in the west tropical Indian Ocean, 1997-2008. Paper IOTC-2008-WPTT-27 prepared for the Indian Ocean Tuna Commission Working Party on Tropical Tunas

Marsac F, LeBlanc LL (2000) ENSO cycle and purse seine tuna fisheries in the Indian Ocean with emphasis on the 1998-1999 La Niña. IOTC Proc 3:354-363

McPhaden MJ (2004) Evolution of the 2002/03 El Niño. Bull Am Meteor Soc 85:677-695. doi:10.1175/ BAMS-85-5-677

Menard F, Marsac F, Bellier E, Cazelles B (2007) Climatic Oscillations and tuna catch rates in the Indian Ocean: a wavelet approach of time series analysis. Fish Oceanogr 16:95-104

Meyers G, McIntosh P, Pigot L, Pook M (2007) The years of El Niño, La Niña, and interactions with the Tropical Indian Ocean. J Climate 20:2872-2880

Miyake MP, Miyabe N, Nakano H (2004) Historical trends of tuna catches in the world. FAO Fish Tech Pap 467:1-74

Murtugudde RG, Signorini SR, Vhristian JR, Busalacchi AJ, McClain CR, Picaut J (1999) Ocean colour variability of the tropical Indo-Pacific basin observed by SeaWiFS during 1997-1998. J Geophys Res 104 (C8):18351-18366

Prince ED, Goodyear CP (2006) Hypoxia-based habitat compression of tropical pelagic fishes. Fish Oceanogr $15: 451-464$

Saji NH, Goswami BN, Vinayachandran PN, Yamagata T (1999) A dipole mode in the tropical Indian Ocean. Nature 401:360-363

Santiago J (1997) The North Atlantic Oscillation and recruitment of temperate tunas. ICCAT Col Vol Sci Pap 48(3):240-249

Sarma V (2006) The influence of Indian Ocean Dipole (IOD) on biogeochemistry of carbon in the Arabian Sea during 1997-1998. J Earth Syst Sci 115(4):433-45

Schaefer KM, Fuller DW, Block BA (2007) Movements, behavior, and habitat utilization of yellowfin tuna (Thunnus albacares) in the northeastern Pacific Ocean, ascertained through archival tag data. Mar Biol 152:503-525

Sharp GD (1992) Fishery catch records, ENSO, and longer term climate change as inferred from fish remains from marine sediments. In: Diaz H, Markgraf V (eds) Paleoclimatology of El Nino-Southern Oscillation. Cambridge University Press, Cambridge, pp 379-417

Stenseth NC, Ottersen G, Hurrel JW, Belgrano A (2004) Marine ecosystems and climate variation. Oxford University Press, New York, p 266

Sugimoto T, Kimura S, Tadokoro K (2001) Impact of El Niño events and climate regime shift on living resources in the western North Pacific. Prog Oceanogr 49:119-127

Sund PN, Blackburn M, Willians F (1981) Tunas and their environment in the Pacific Ocean: a review. Oceanogr Mar Biol Annu Rev 19:443-512

Tian Y, Kidokoro H, Watanabe T, Iguchi N (2008) The late 1980s regime shift in the ecosystem of Tsushima Warm Current in the Japan/East Sea: evidence from historical data and possible mechanisms. Prog Oceanogr 77:127-145 
Torrence C, Compo GP (1998) A practical guide to wavelet analysis. Bull Am Meteorol Soc 79:61-78

Torres-Orozco E, Muhlia-Melo A, Trasviña A, Ortega-Garcia S (2006) Variation in yellowfin tuna (Thunnus albacares) catches related to El Niño-Southern Oscillation events at the entrance to the Gulf of California. Fish Bull 104:197-203

Trenberth KE (1991) General characteristics of El Niño-Southern Oscillation. In: Glantz MH, Katz RW, Nicholls N (eds) Teleconnections linking worldwide climate anomalies. Scientific basis and societal impact. Cambridge University Press, Cambridge, pp 13-42

Wood SM (2006) Generalized additive models, an introduction with R. Chapman and Hall, London, 392pp

Yamagata T, Behera SK, Luo JJ, Masson S, Jury MR, Rao SA (2004) Coupled ocean-atmosphere variability in the tropical Indian Ocean. Geophys Mongr 147:189-212 